\title{
PRODUÇÃO DE BIODIESEL POR TRANSESTERIFICAÇÃO DA GORDURA SUÍNA
}

\author{
A. C. STAFUSSA ${ }^{1}$, J. L. C.W. PIMENTA ${ }^{1}$, C. M. OLIVEIRA ${ }^{1}$, P. R. PARAÍSO ${ }^{1}$, L. M. M. JORGE \\ ${ }^{1}$ Universidade Estadual de Maringá, Departamento de Engenharia Química \\ E-mail para contato: 1mmj@deq.uem.br
}

\begin{abstract}
RESUMO - Geralmente o biodiesel é produzido a partir da transesterificação de gorduras vegetais em meio básico homogêneo. Apesar do estudo destes sistemas serem amplamente apresentado em literatura, pouco se encontra a respeito da produção de biodiesel a partir de gordura suína. Neste contexto, o presente trabalho tem como objetivo principal pesquisar a produção de biodiesel oriundo da gordura suína. Para tal, efetuaram-se diversos ensaios variando-se a razão molar gordura: metanol, a massa de catalisador $(\mathrm{NaOH})$, tempo de agitação e temperatura reacional. A partir destes ensaios as amostras de biodiesel foram analisadas quanto à sua viscosidade dinâmica, ponto de névoa e ponto de fluidez, constatando-se que não houve alterações consideráveis destas propriedades, sendo que todas encontravam-se dentro das normas especificadas para o biodiesel comercial.
\end{abstract}

Palavras chave: Biodiesel, gordura suína, transesterificação.

\section{INTRODUÇÃO}

O advento do desenvolvimento social e tecnológico, juntamente com o crescente aumento da população mundial, trouxe consigo o aumento de demanda de energia e o aumento da poluição. Considerando o agravamento dos problemas ambientais advindos do uso de combustíveis fósseis, a busca por fontes de energia limpas, renováveis e ambientalmente amigáveis, vem crescendo acentuadamente. Neste cenário o biodiesel se destaca, sendo uma alternativa de menor impacto ambiental e renovável, utilizado no setor de transporte e geração de energia (KNOTHE et al., 2006).

O biodiesel apresenta como vantagem o fato de conseguir ser produzido a partir de diversas matérias-primas, as quais incluem a maioria de óleos vegetais como os de soja, mamona, dendê, gorduras de origem animal e também óleos de descarte (JANAUN e ELLIS, 2010).

Geralmente o biodiesel é produzido a partir da transesterificação de óleos vegetais em meio básico homogêneo (KNOTHE et al.,2006). Apesar do estudo deste sistema ser amplamente apresentado em literatura, pouco se encontra a respeito da produção de biodiesel a partir de gordura animal. 
Dentre as gorduras animais, destaca-se a gordura proveniente dos suínos. Considerada a carne mais consumida no mundo (ALMEIDA, 2008), esta apresenta gordura residual suficiente para a produção de biodiesel em larga escala.

Segundo Ma e Hanna (1999), sabe-se que alguns procedimentos realizados no biodiesel oriundo de óleos vegetais não são apropriados para as gorduras animais, devido às diferenças existentes nas propriedades de cada matéria-prima. Logo, tornam-se necessários novos estudos em relação à utilização da gordura animal, pois a utilização desse resíduo além de reduzir os custos de produção do biodiesel, contribuiria para amenizar os impactos ambientais oriundos do seu descarte.

O processo de produção de biodiesel inclui a reação de transesterificação, onde as moléculas de triglicerídeos reagem com as moléculas de álcool para produzir ésteres (biodiesel) e glicerol, conforme a reação:

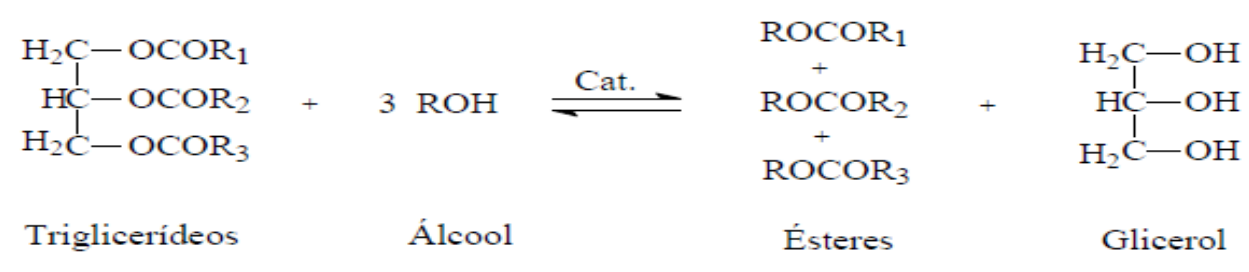

Além da gordura como matéria-prima há a necessidade da adição de álcool no meio reacional a fim de ocorrer a solubilização. Para Ma e Hanna (1999), o metanol e o etanol são os mais utilizados, destacando-se o metanol devido à facilidade de separação dos produtos. A reação de transesterificação pode ser catalisada com ácidos, bases ou enzimas. Ou ainda, pode ocorrer sem catalisador se estiver em condições supercríticas. Morais et al. (2010) afirma que dentre os catalisadores alcalinos, os mais utilizados são o hidróxido de sódio e o de potássio. Entretanto os catalisadores básicos são muito sensíveis à presença de ácidos graxos livres e a água nas matérias-primas lipídicas. Para Vieitez et al.(2010) a reação de transesterificação catalisada por acido é mais lenta se comparada com a catalisada por base. Kiss (2010) afirma que catalisadores enzimáticos possuem um alto valor, sendo desvantajoso em escala industrial.

Diante de todos esses fatores, o desafio está em procurar métodos de produção mais competitivos com o diesel, buscando fontes de matérias-primas adequadas que forneçam um combustível de ótima qualidade e que seja viável industrialmente. Neste contexto, o objetivo deste estudo foi avaliar a viabilidade da produção de biodiesel a partir da transesterificação, utilizando como matéria-prima a gordura suína e o metanol, com o catalisador básico hidróxido de sódio.

\section{METODOLOGIA}

\subsection{Síntese de Biodiesel}

A síntese de biodiesel foi realizada a partir de gordura suína e metanol. A reação ocorreu na presença de catalisador, nesse caso hidróxido de sódio, dissolvido em metanol. A reação foi conduzida em um erlenmeyer colocado sob uma chapa aquecedora com agitação magnética. Foram feitos ensaios variando-se a razão molar óleo: metanol nas proporções de 
1:6 e 1:9, com tempo de agitação de 40 minutos e 90 minutos. As massas de catalisador utilizadas foram de $0,5 \%$ e $1 \%$ em relação à massa de gordura suína. Utilizou-se as temperaturas de $45^{\circ} \mathrm{C}$ e $55^{\circ} \mathrm{C}$.

Ao término da reação a mistura foi deixada em repouso para a decantação das fases de biodiesel e subprodutos, os quais foram separadas com o auxilio de um funil de separação. Posteriormente, as amostras de biodiesel foram lavadas uma única vez com solução salina $(\mathrm{NaCl}, 1 \%)$, decantadas e separadas. O procedimento de lavagem foi repetido mais algumas vezes utilizando água deionizada até que a separação de fases ocorresse e as fases apresentassem aspecto translúcido. Após a separação da água e do biodiesel, este foi deixado para secar em um dessecador e então guardado para análises futuras.

\subsection{Procedimento Experimental para a Caracterização do Biodiesel}

Viscosidade: a viscosidade dinâmica de cada amostra foi obtida a partir do aquecimento da amostra desde a temperatura ambiente até a temperatura de interesse $\left(27-45^{\circ} \mathrm{C}\right)$, de forma lenta e gradual numa chapa de aquecimento. Após a amostra ter alcançado a condição de equilíbrio térmico efetuou-se a medida da viscosidade com o auxilio de um viscosímetro de bolas (marca Brookfield modelo KF40).

Ponto de fluidez e névoa: a fim de determinar o ponto de fluidez e o ponto de névoa do biodiesel produzido, adicionou-se uma amostra de biodiesel num béquer sobre um banho termostatizado com um termopar tipo T inserido na amostra. Para a determinação do ponto de fluidez, resfriou-se lentamente a amostra, observando-se a fluidez desta em pequenos intervalos de temperatura (mediante a inclinação do béquer em $45^{\circ}$ ) a fim de analisar a facilidade de escoamento, definindo-se o ponto de fluidez como sendo a menor temperatura em que ainda se observava o movimento do fluido. Para a aferição do ponto de névoa, a amostra passou por um resfriamento controlado até que se percebesse a turvação da amostra.

\section{RESULTADOS}

Ao todo foram feitos nove ensaios reacionais, nos quais variaram-se a razão molar, o tempo de agitação, a massa de catalisador e a temperatura, conforme especificações indicadas na Tabela 1.

Tabela1- Especificações das amostras

\begin{tabular}{cccccc}
\hline Amostra & $\begin{array}{c}\text { Massa de } \\
\text { óleo }(\mathrm{g})\end{array}$ & $\begin{array}{c}\text { Massa de } \\
\text { metanol }(\mathrm{g})\end{array}$ & $\begin{array}{c}\text { Massa } \\
\text { catalisador }(\mathrm{g})\end{array}$ & $\begin{array}{c}\text { Tempo de } \\
\text { agitação }(\mathrm{min})\end{array}$ & $\begin{array}{c}\text { Temperatura } \\
\left({ }^{\circ} \mathrm{C}\right)\end{array}$ \\
\hline 1 & 80,3 & 19,79 & 0,8341 & 90 & 55 \\
2 & 80,2 & 19,21 & 0,4426 & 40 & 55 \\
3 & 80,2 & 18,77 & 0,8036 & 40 & 55 \\
4 & 80,5 & 19,60 & 0,4418 & 90 & 55 \\
5 & 82,0 & 29,96 & 0,4244 & 40 & 55 \\
6 & 80,9 & 29,20 & 0,8444 & 90 & 55 \\
7 & 81,8 & 29,12 & 0,9049 & 90 & 45 \\
8 & 81,1 & 32,72 & 0,9700 & 40 & 55 \\
9 & 81,3 & 30,95 & 0,4097 & 90 & 55 \\
\hline
\end{tabular}


Conforme ilustrado na Figura 1, pode-se constatar que a viscosidade do biodiesel produzido decresce quase linearmente com a temperatura para todas as amostras estudadas, não apresentando variações significativas numa dada temperatura, independentemente das condições reacionais.

Figura 1 - Viscosidade em função da temperatura.

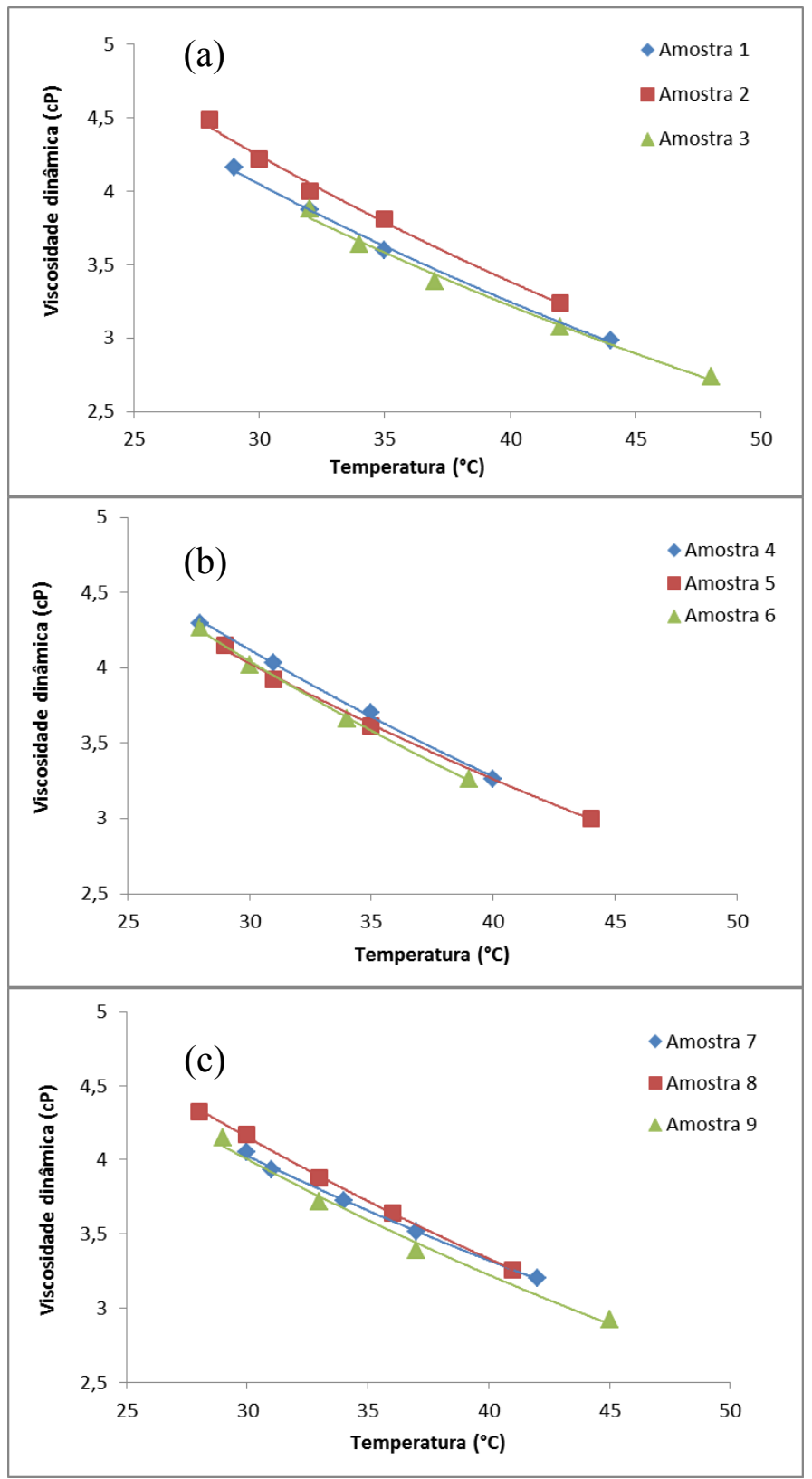

Com o intuito de comparar com valores de viscosidade de literatura (Moreira, 2008), efetuou-se a avaliação da viscosidade de cada uma das amostras indicadas na Figura 1 a $40^{\circ} \mathrm{C}$, mediante interpolação, sendo os resultados apresentados na Tabela 2. 
Tabela 2 - Viscosidade dinâmica e cinemática das amostras na temperatura padrão de $40^{\circ} \mathrm{C}$, determinadas a partir dos gráficos plotados

\begin{tabular}{ccc}
\hline Amostra & $\begin{array}{c}\text { Viscosidade dinâmica a } 40^{\circ} \mathrm{C} \\
(\mathrm{g} /(\mathrm{cm} . \mathrm{s}))\end{array}$ & $\begin{array}{c}\text { Viscosidade cinemática a } \\
40^{\circ} \mathrm{C}\left(\mathrm{mm}^{2} / \mathrm{s}\right)\end{array}$ \\
\hline 1 & 0,0323099 & 3,765723 \\
2 & 0,0338195 & 3,913841 \\
3 & 0,03178552 & 3,700336 \\
4 & 0,03266968 & 3,77296 \\
5 & 0,03243097 & 3,779402 \\
6 & 0,03226128 & 3,75581 \\
7 & 0,0332039 & 3,836694 \\
8 & 0,03333175 & 3,865716 \\
9 & 0,031518970 & 3,644422 \\
\hline
\end{tabular}

Conforme pode-se observar na Tabela 3, tanto os pontos de névoa como os pontos de fluidez variaram muito pouco em função das condições reacionais (Tabela1).

Tabela 3 - Ponto de névoa e ponto de fluidez encontrados para cada amostra

\begin{tabular}{ccc}
\hline Amostra & Ponto de névoa $\left({ }^{\circ} \mathrm{C}\right)$ & Ponto de fluidez $\left({ }^{\circ} \mathrm{C}\right)$ \\
\hline 1 & 16 & 5 \\
2 & 15 & 5 \\
3 & 16 & 6 \\
4 & 15 & 5 \\
5 & 16 & 5 \\
6 & 16 & 6 \\
7 & 16 & 6 \\
8 & 15 & 6 \\
9 & 14 & 5 \\
\hline
\end{tabular}

De posse dos resultados apresentados na Tabela 2, e a partir das informações disponíveis por Moreira (2008), pôde-se constatar que os valores das viscosidades das amostras estão dentro da faixa considerada ideal para o biodiesel: entre $3,5 \mathrm{~mm}^{2} / \mathrm{s} \mathrm{e} 5 \mathrm{~mm}^{2} / \mathrm{s}$. Após todas as reações formaram-se duas fases, uma predominantemente de biodiesel e outra com glicerol. Entretanto foi percebido que nas amostras contendo 1\% de catalisador em massa (amostras 1, 3, 6, 7 e 8) a fase de glicerol mostrou-se pastosa, o que pode dificultar uma posterior separação industrial por decantação.

Os pontos de fluidez e névoa também se mostraram compatíveis frente aos dados apresentados por Moser (2008), Vyas et al. (2009), Mittelbach e Remschmidt (2005), os quais afirmam que o ponto de fluidez para o biodiesel produzido com banha é cerca de $6^{\circ} \mathrm{C}$ e o ponto de névoa está contido no intervalo de $12^{\circ} \mathrm{C} \mathrm{a} 17^{\circ} \mathrm{C}$. 


\section{CONCLUSÃO}

As nove amostras de biodiesel obtidas em diferentes condições reacionais, encontravam-se de acordo com as especificações do biodiesel industrial, apontando para a viabilidade da produção industrial de biodiesel de gordura suína.

$\mathrm{Na}$ faixa de condições reacionais exploradas, constatou-se que as amostras contendo $1 \%$ de catalisador, conduzem a formação de uma fase sólida pastosa rica em glicerol, o que pode dificultar uma posterior separação por decantação em escala industrial.

A condição operacional mais favorável para a produção de biodiesel será aquela em que se gastará o menos possível de matéria-prima, e, nesse caso, a reação mais conveniente foi aquela em que se utilizou razão molar 1:6 de gordura suína: metanol, 0,5\% de catalisador em massa de sebo, $55^{\circ} \mathrm{C}$ e 40 minutos de reação sob agitação.

\section{REFERÊNCIAS}

ALMEIDA, G. V. B. P. Biodigestão Anaeróbicas na Suinocultura. São Paulo, 2008.

JANAUN, J., \& ELLIS, N. Perspectives on biodiesel as a sustainable fuel. Renewable and Sustainable Energy Reviews, v. 14, p. 1312-1320, 2010.

KISS, A. A. Separative reactors for integrated production of bioethanol and biodiesel. Computers and Chemical Engineering, v. 34, p. 812-820, 2010.

KNOTHE, G.; GERPEN, J. V.; KRAHL, J.; RAMOS, L. P. Manual do Biodiesel. SãoPaulo: Blücher, 2006. 352 p.

MA, F.; HANNA, M. A. Biodiesel production: a review. Bioresource Technology, v. 70, p. 1$15,1999$.

MITTELBACH, M., and REMSCHMIDT, C. Biodiesel the Comprehensive Handbook, Second Edition. Boersedruck Ges. m.b.H, Vienna, 2005.

MORAIS, S.; MATA, T. M.; MARTINS, A. A.; PINTO, G. A.; COSTA C. A. V. Simulation and life cycle assessment of process design alternatives for biodiesel production from waste vegetable oils. Journal of Cleaner Production, v. 18, p.1251-1259, 2010.

MOREIRA, SÉRGIO; Estudo da Influência do Biodiesel nas emissões poluentes de um motor turbo Diesel; Dissertação de Mestrado da Faculdade de Engenharia da Universidade do Porto; Fevereiro de 2008; Porto.

MOSER, B.R. Influence of blending canola, palm, soybean, and sunflower oil methyl esters on fuel properties of biodiesel. Energy \& Fuels, 2008.

VIEITEZ, I.; SILVA, C.; ALCKMIN, I.; BORGES, G. R.; CORAZZA, F. C., OLIVEIRA, J. V. Continuous catalyst-free methanolysis and ethanolysis of soybean oil under supercritical alcohol/water mixtures. Renewable Energy, v. 35 , p. 1976-1981, 2010.

VYAS, AMISH P., SUBRAHMANYAM, N., and PATEL, PAYAL A. Production of biodiesel through transesterification of Jatropha oil using KNO3/A12O3 solid catalyst. Fuel ,p 625-628, 2009. 